\title{
Biodiversity Assessment of Paddy Field Ecosystem using Birds as a Biodiversity Indicator
}

\author{
G.W.R.W.M.R.M.W.K. Kirinde ${ }^{1^{*}}$, M.I.M. Mowjood ${ }^{2}$, N.D.K Dayawansa ${ }^{2}$ \\ ${ }^{1}$ Post Graduate Institute of Agriculture, University of Peradeniya, Sri Lanka \\ ${ }^{2}$ Department of Agricultural Engineering, University of Peradeniya, Sri Lanka \\ *1986mayuri@gmail.com
}

\begin{abstract}
Biodiversity assessment is considered in making decisions concerning declaration of protected areas, management of nature reserves and assessment of the success of management decisions within a particular area. Biodiversity indicators are used as measures of biodiversity. Degree of disturbance or fragmentation of a definite habitat can be measured using specific indicator species. A variety of invertebrates and vertebrates are widely used as indicators of biodiversity. Birds are one of the best species for the national and international biodiversity schemes to be used as a biodiversity indicator.
\end{abstract}

This study focused on the use of birds as an ecological indicator to assess the paddy field ecosystem. The study was carried out in a minor irrigation system in Awlegama Agrarian Service area in Wariyapola Divisional Secretariat. Bayawa was the selected tank with nearly a 38 ha of command area. A standard fixed-radius point count method with the radius set at $25 \mathrm{~m}$ was used to sample birds in the paddy field ecosystem. Shanon index was used to explain the results. During a single rice cycle, rice plants undergo three main phenological stages namely; vegetative, reproductive and ripening. All these stages are influenced by farming practices such as tillage, irrigation, crop establishment, agrochemical application and weeding. Different stages with different farming practices create distinct habitats for various bird species. According to the results, the highest Shanon index value (highest diversity) was recorded during the vegetative stage. Birds' diversity had a significant, strong $(\mathrm{p}=0.05)$ negative correlation with the age of the paddy. Initial land preparation and vegetative stages provide more food sources for the predatory birds who feed on worms, insects and snails; some of whom act as pests of paddy. Mixing of upper and the sub-soil layers in land preparation stages supply more feed for predatory birds. Cattle Egret, Red Wattled Lapwing, Intermediate Egrets, Indian Pond Heron, Black Necked Stroke were in abundance at land preparation and vegetative stage. Yellow crowned woodpecker and White throated munia were recorded during the later stages. A variety of management practices such as land preparation, crop establishments, irrigation, nutrient and pest management, harvesting within the paddy field facilitate to create different habitats with different eco systems and suitable food for bird species. The birds as a biodiversity indicator, symbolise the ecosystem and it reflects the existing condition of an ecosystems. A detailed study will reveal how these birds would help to manage different pests in the paddy fields to bring benefits to the farmers.

Keywords: Biodiversity indicator, Ecosystem, Paddy field, Birds, Cattle Egret 